\title{
Utjecaj folijarne gnojidbe na osnovni kemijski sastav mošta cv. Malvazije istarske (Vitis vinifera L.)
}

\section{Sažetak}

'Malvazija istarska' (Vitis vinifera L.) jedna je od najznačajnijih bijelih sorata u Hrvatskoj. Njezina kvaliteta prepoznata je kako u Hrvatskoj, tako i u cijelom svijetu. Stoga se domaći proizvođači sve češće odlučuju za proizvodnju vina i pjenušaca iz ove sorte. Mošt za proizvodnju baznoga vina za pjenušce po svome sastavu trebao bi zadovoljavati svojstva kao što su niža pH vrijednost i sadržaj šećera, te viši sadržaj ukupne kiselosti s većim udjelom vinske kiseline, naspram jabučne. S obzirom da se 'Malvazija istarska' uzgaja pretežito u Istri, gdje je klima mediteranska, a najzastupljenije tlo crvenica teško je zadovoljiti sva navedena svojstva, posebice u suhim i vrućim godinama. Stoga, cilj ovog istraživanja bio je utvrditi mogućnost pozitivnog djelovanja folijarne gnojidbe na navedena svojstva. Pokus je postavljen na sorti Malvazija istarska na podlozi SO4 2013. s četiri gnojidbena tretmana (T1- NPK, T2 NPK + Agromag 6L (6\% MgO), T3 - NPK + Agromag 6L + Fosforo 30L (30\% P2O5) i T4 - NPK + Agromag $6 L+$ Fosforo $30 L+$ Bio Prot) u tri ponavljanja po slučajnom bloknom rasporedu (RCBD). Sveukupno određena $\mathrm{pH}$ vrijednost u moštu kretala se od 3,02 do 3,29, ukupna kiselost u moštu od 7,80 do 9,03 $\mathrm{g} / \mathrm{L}$, a sadržaj šećera od 76,00 - 81,00 ${ }^{\circ}$ Oe. Najveća utvrđena koncentracija vinska kiselina bila je 4,49 $\mathrm{g} / \mathrm{l}$ u tretmanu T3, koji je imao i najnižu utvrđenu koncentraciju jabučne kiseline 1,40 g/L. Značajan pozitivan utjecaj na sva svojstva imao je tretman T4.

Ključne riječi: magnezij, fosfor, ukupna kiselost, bazna vina, pjenušava vina

\section{Uvod}

'Malvazija istarska' (Vitis vinifera L.) smatra se autohtonom istarskom sortom, koja daje visokokvalitetna vina s visokim udjelom šećera u grožđu i prosječne ukupne kiselosti 5,0 - 6,5 g/L, te $\mathrm{pH}$ većim i od 3,3 (Ilak Peršurić i sur., 2006). Najvećim dijelom uzgaja se u Istri na crvenici pod utjecajem mediteranske klime (Maletić i sur., 2015). Crvenica je nekarbonatno tlo, poliedrične strukture i teže teksture (Bogunović i Bensa, 2005). S obzirom da minerali iz tla imaju značajan utjecaj na osnovni kemijski sastav mošta, Čoga i sur. (2009) utvrdili su postojanje pozitivne korelacije između P, Ca i Mg, i šećera u moštu, te negativne korelacije između sadržaja tih minerala i ukupne kiselosti. Mnogi autori smatraju kako je vinova loza biljka kalija, no visok sadržaj $\mathrm{K}$ u lišću i bobicama povezan je s visokim pH mošta (White, 2003). Također visoke temperature i male količine oborina u vegetaciji mogu rezultirati nižim udjelom pojedinačnih organskih kiselina u grožđu što je naročito izraženo u sušnim godinama. Prema podacima Državnog hidrometeorološkog zavoda za postaju Poreč u usporedbi s višegodišnjim klimatološkim podatcima (1981.-2010.) utvrđeno je kako je 2013. godine, kad je provedeno istraživanje, u periodu od ožujka do rujna sumu oborina bila relativno slična. Međutim, izrazito niska suma oborina zabilježena je u travnju i srpnju, a srednje mjesečne temperature tijekom vegetacijskog razdoblja 2013. godine bile su više od višegodišnjeg prosjeka. Kako dostupnost minerala u tlu ovisi o

dipl. ing. agr. Ana Peršurić Palčić, Pjenušci Peršurić d.o.o., Pršurići 5a, HR-52463 Višnjan, Hrvatska (ana@misal.hr) prof.dr.sc.AnaJeromel, prof.dr.sc. Marija Pecina, prof.dr.sc. Mirjana HerakĆustić,

Sveučilište u Zagrebu, Agronomski fakultet, Svetošimunska cesta 25, HR-10000 Zagreb, Hrvatska dr.sc. Igor Palčić, Institut za poljoprivredu i turizam, Karla Huguesa 8, HR-52440 Poreč, Hrvatska dr.sc. David Gluhić, Veleučilište u Rijeci, Poljoprivredni odjel Poreč, Karla Huguesa 6, HR-52440 Poreč, Hrvatska Autor za korespondenciju: ana@misal.hr 
tipu i sastavu tla, vlazi u tlu i fiziološkom stanju vinove loze (Fregoni, 2008), folijarna gnojidba je jedan od načina na koji se može osigurati dostatne količine minerala vinovoj lozi. Palčić (2015) navodi da folijarna primjena minerala i aminokiselina pozitivno utječe na minerale i organoleptička svojstva vina 'Malvazije istarske'.

'Malvazija istarska' osim za proizvodnju vina u novije vrijeme se koristi i za proizvodnju pjenušaca koji su sve popularnije ljetno piće. U proizvodnji pjenušaca vrlo je bitno proizvesti bazno vino na čiju kvalitetu direktno utječe osnovni kemijski sastav mošta. lako se zakonski ne razlikuje kemijski sastav mošta za proizvodnju baznog vina od kemijskog sastava mošta za proizvodnju mirnih vina u praksi je poznato da postoje neka odstupanja. Jedan od najvažnijih kriterija u proizvodnji pjenušavih vina je viša ukupna kiselost koja osigurava njegovu svježinu. Stoga su toplija mediteranska područja nešto zahtjevnija u proizvodnji pjenušaca (Zoecklein, 2002). Osim toga, važnu ulogu u kvaliteti baznog vina ima i pH vrijednost mošta, obzirom da previsoka vrijednost može nepovoljno utjecati na svježinu i potencijal starenja kao i mikrobiološku stabilnost. Visoka pH vrijednost mošta rezultat je prekomjerne količine $\mathrm{K}$ u grožđu, koja se javlja kod neadekvatne primjene u vinogradu (Daudt i Fogaca, 2008) zbog blokiranja usvajanja Mg, a samim time i fotosinteze obzirom da Mg ima strukturnu ulogu u klorofilu (Roubelakis-Angelakis, 2009). Kao posljedica javlja se nepovoljan omjer vinske i jabučne kiseline zbog taloženja kalijevog bitartarata tijekom vinifikacije, te smanjenja ukupne kiselosti. Osim količine $\mathrm{K}$ i Mg u tlu, značajan je i njihov omjer, jer višak $\mathrm{K}$ dovodi do preširokog odnosa s Mg (Herak Ćustić i sur., 2008). Jones i sur. (2014) bavili su se ulogom i značajem tehnike vinogradarenja na osnovni kemijski sastav mošta (ukupne kiselosti, pH vrijednost i šećere) u proizvodnji pjenušaca, no nisu proučavali utjecaj folijarne gnojidbe kao jedne od potencijalno uspješnih mjera kojima bi se ostvario pozitivan utjecaj. Cilj ovog istraživanja bio je proučiti mogućnosti pozitivnog djelovanja folijarne gnojidbe vinove loze na postizanje poželjnih svojstava u proizvodnji mošta za bazna vina.

\section{Materijali i metode}

Istraživanje je 2013. provedeno u vinogradu u punoj rodnosti starosti 4 godine na sorti Malvazija istarska (Vitis vinifera L.) na podlozi SO4. Vinograd se nalazi na zapadnom dijelu Istre u općini Višnjan i koristi se isključivo za proizvodnju grožđa namjenjenog proizvodnji pjenušaca. Tlo na lokalitetu je duboka crvenica slabo kisele reakcije, dobro opskrbljena dušikom i kalijem, a siromašna fosforom i humusom, te s vrlo malim udjelom skeleta. Opterećenje u rezidbi bilo je isto za sve trsove u pokusu s 22 pupa po trsu, a uzgojni oblik dvokraki Guyot.

Odabrana su četiri gnojidbena tretmana: T1 - NPK, T2 - NPK + Mg, T3 - NPK + Mg + P, i T4 $\mathrm{NPK}+\mathrm{Mg}+\mathrm{P}+$ biostimulator, u 3 repeticije. Svi tretmani gnojeni su s $500 \mathrm{~kg} / \mathrm{ha}$ NPK gnojivom formulacije 7-14-21 u veljači u tlo. Uz to u tretmanu T2 uz NPK gnojivo koristio se i magnezijev pripravak Agromag 6L (6\% MgO), u dozi od $5 \mathrm{~kg} /$ ha folijarno. U tretmanu T3 uz NPK i Agromag $6 \mathrm{~L}$ gnojivo dodavao se pripravak fosfora Fosforo $30 \mathrm{~L}\left(30 \% \mathrm{P}_{2} \mathrm{O}_{5}\right)$ u količini od $3 \mathrm{~kg} / \mathrm{ha}$ folijarno. Uz sve navedene pripravke T4 je imao još i biostimulator Bio Prot u dozi od $2 \mathrm{~kg} / \mathrm{ha}$ folijarno. Bio Prot je tekući pripravak s ekstraktom algi vrste Ascophyllum nodosum, na bazi organskog dušika (4\%), organskog ugljika (12\%) i aminokiselina (lizin 1,3\%, asparaginska kiselina 1,7\%, glutaminska kiselina 3,2 \%, hidroksiprolina 2,5\%, valin 0,8 \%, izoleucin 0,5 \%, fenilalanin 0,7 \%, histidin $0,3 \%$, treonin $0,3 \%$, prolin $4,2 \%$, alanin $2,8 \%$, metionin $0,2 \%$, triptofan $0,02 \%$, arginin $2 \%$, serin $0,5 \%$, glicin 7,8 \%, cistein 0,09 \%, leucin 1,1\%, tirozin 0,4\%). Primjenjivale su se minimalne količine folijarnih gnojiva prema preporuci proizvođača. 
Tretiranje se provelo četiri puta tijekom vegetacije u ključnim fenofazama za vinovu lozu: prije cvatnje (svibanj), u fazi zametanja bobica (srpanj) i u šari (kolovoz), te nakon berbe (rujan).

Pokus je bio postavljen po slučajnom bloknom rasporedu $(R C B D)$ s pokusnim parcelama po 14 trsova ujednačene kondicije i zdravstvenog stanja. Kako bi se utvrdio kemijski sastav mošta uzeti su uzorci mošta u fazi berbe, dok je za organske kiseline provedeno uzorkovanje bobica u dva termina. U prvom terminu uzeti su uzorci 7 dana nakon 3. tretiranja, te u drugom terminu u trenutku berbe i to po 100 bobica po tretmanu, uzetih sa 20 grozdova (pet bobica po grozdu) sa različitih pozicija (Zoecklein i sur., 1995). Berba grožđa obavljala se ručno u trenutku kada je grožđe bilo tehnološki zrelo za proizvodnju baznog vina. Vinifikacija se provela na jednak način za sve tretmane.

Analiza osnovnog kemijskog sastava mošta (ukupna kiselost, $\mathrm{pH}$, šećeri) provedena je prema metodi O.I.V. za analizu mošta i vina (O.I.V., 2007) za svaki tretman u 3 repeticije. Metodom tekućinske kromatografije visoke djelotvornosti (HPLC) odredile su se pojedinačne organske kiseline u svježem uzorku mošta sa 2 uzorkovanja za 4 tretmana (Berente i sur. 2001).

Dobiveni podaci su statistički obrađeni uz primjenu statističkih softvera CoStat, 2005. i SAS Institute Inc. 2015. Učinci folijarne gnojidbe na osnovna kemijska svojstva mošta statistički su obrađeni prema osnovnom modelu RCBD i jednosmjerne analize varijance (ANOVA). Za testiranje razlika u prosječnim vrijednostima učinaka proveo se Tukey's test.

\section{Rezultati i rasprava}

Provedenim istraživanjem utjecaja folijarne gnojidbe na osnovni kemijski sastav mošta cv. 'Malvazije istarske' (Vitis vinifera L.) u 2013. godini utvrđeno je da postoji značajan utjecaj folijarne gnojidbe na pH vrijednost mošta, ukupnu kiselost i sadržaj šećera u 2013. godini (tablica 1.). Najizraženiji utjecaj je imala folijarna gnojidba na ukupnu kiselost.

Tablica 1. Utjecaj folijarne gnojidba na pH vrijednost mošta, ukupnu kiselost g/L i sadržaj šećera ( $\left.{ }^{\circ} \mathrm{Oe}\right)$

Table 1. Effect of foliar fertilization on $\mathrm{pH}$ value, total acids $\mathrm{g} / \mathrm{L}$ and sugar content $\left({ }^{\circ} \mathrm{Oe}\right)$ of must

\begin{tabular}{lcc}
\hline Svojstvo/Property & p-vrijednost/p-value & Signifikantnost/Significance \\
\hline pHvrijednost/pH valute & 0,0242 & $*$ \\
\hline Ukupna kiselost/Total acid g/L & 0,0006 & $* * *$ \\
\hline Šećer ${ }^{\circ}$ Oe/ Sugar ${ }^{\circ}$ Oe & 0,0021 & $* *$ \\
\hline
\end{tabular}

NS nije signifikantno; ${ }^{*}$ signifikantno na razini 0,$05 ;{ }^{* *}$ signifikantno na razini 0,$01 ;{ }^{* * *}$ signifikantno na razini $<0,01 ; n=12$

NS not significant; * significant at 0.05 level; ** significant at 0.01 level; *** significant at $<0.01 ; n=12$

Iz grafikona 1. vidljivo je da je tretman T4 imao statistički najmanju prosječnu pH vrijednost od 3,09, što predstavlja poželjanu vrijednost za mošt od kojeg se proizvodi bazno vino za pjenušac. Tretman T2 imao je prosječnu pH vrijednost od 3,17, dok je kod T3 ista utvrđena u iznosu 3,13. Najviša prosječna pH vrijednost izmjerena je kod tretmana T1 te je iznosila 3,23. Jasno je vidljivo da folijarna gnojidba pozitivno utječe na smanjenje $\mathrm{pH}$ vrijednosti. 


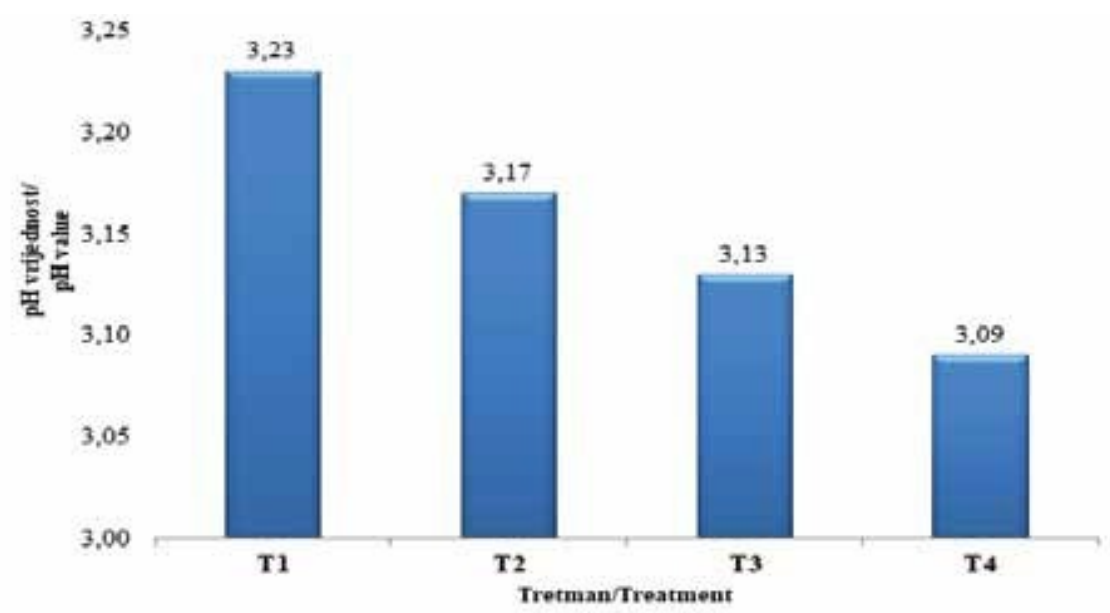

Grafikon 1. Prosječna pH vrijednost mošta pri primijenjenim tretmanima

Graph 1. Average must $\mathrm{pH}$ value by the applied treatments

$T 1-N P K, T 2-N P K+M g, T 3-N P K+M g+P, i T 4-N P K+M g+P+$ biostimulator

Na ukupnu kiselost najpoželjniji utjecaj imao je tretman T4, kod kojega je ona iznosila 8,70 $\mathrm{g} / \mathrm{L}$, što je statistički najviša prosječna vrijednost. Tretman T2 također je imao visoku prosječnu vrijednost ukupne kiselosti od 8,55 g/L. Stoga oba tretmana imaju vrlo značajan utjecaj na ukupnu kiselost. Značajniji utjecaj u vidu više ukupne kiselosti nije uočen pri tretmanima T1 (7,95 g/L) iT3 (8,05g/L). (grafikon 2.)

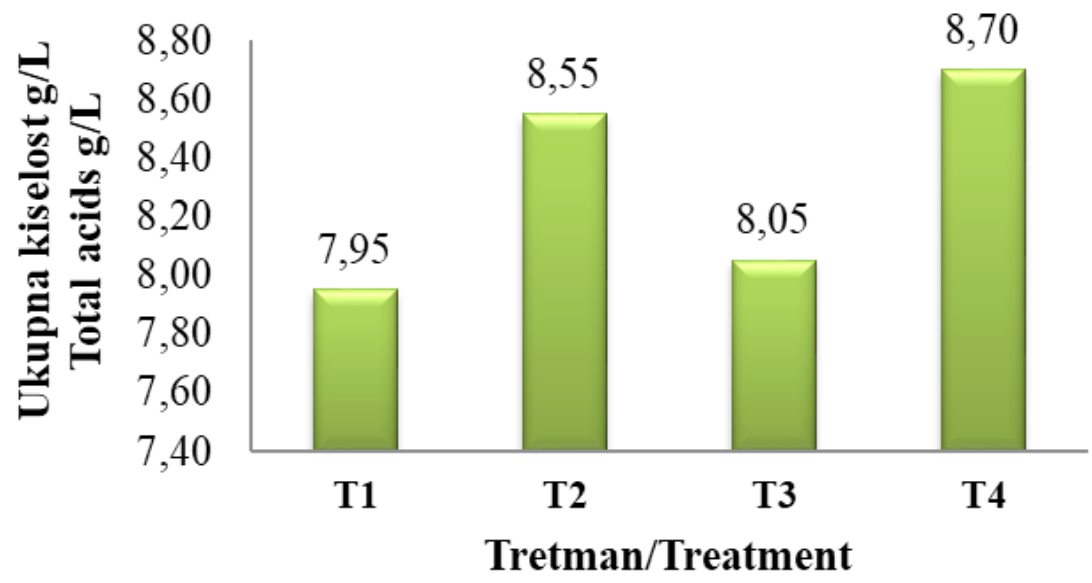

Grafikon 2. Prosječna ukupna kiselost mošta (g/L) pri primijenjenim tretmanima Graph 2. Average must total acid concentration $(\mathrm{g} / \mathrm{L})$ by the applied treatments $T 1-N P K, T 2-N P K+M g, T 3-N P K+M g+P, i T 4-N P K+M g+P+$ biostimulator

Najviši sadržaj šećera imao je tretman T2 i iznosio je $80,00^{\circ}$ Oe. Iz grafikona 3. može se zaključiti da tretmani $\mathrm{T3}\left(78,00^{\circ} \mathrm{Oe}\right) \mathrm{i} 44\left(77,67^{\circ} \mathrm{Oe}\right)$ imaju za proizvodnju pjenušaca najpovoljniji utjecaj na sadržaj šećera, jer je kod njih on najniži i predstavlja statistički značajnu razliku. Nešto viši bio je kod tretmana $11\left(78,83^{\circ} \mathrm{Oe}\right)$. 




Grafikon 3. Prosječni sadržaj šećera $\left({ }^{\circ} \mathrm{Oe}\right)$ u moštu pri primijenjenim tretmanima Graph 3. Average must sugar content ${ }^{\circ} \mathrm{Oe}$ by the applied treatments $T 1-N P K, T 2-N P K+M g, T 3-N P K+M g+P, i T 4-N P K+M g+P+$ biostimulator

Iz rezultata dobivenih analizom organskih kiselina može se zaključiti da tretmani T3 i T4 pokazuju najbolje rezultate za proizvodnju pjenušavih vina. Odnosno, kod navedenih tretmana uočeno je da je koncentracija vinske kiseline najviša, dok je koncentracija jabučne kiseline najniža. U tretmanu T1 izmjereno je 4,07 g/L vinske kiseline, te 1,67 g/L jabučne. Tretman T2 imao je 4,09 g/L vinske i 1,79 g/L jabučne kiseline. Koncentracija vinske izmjerena u T3 iznosila je 4,49 g/L, a u T4 4,41 g/L. Sličan rezultat utvrđen je i kod koncentracija jabučne kiseline i to za T3 1,40 g/L, te 1,49 g/L pri tretmanu T4. (grafikon 4.).

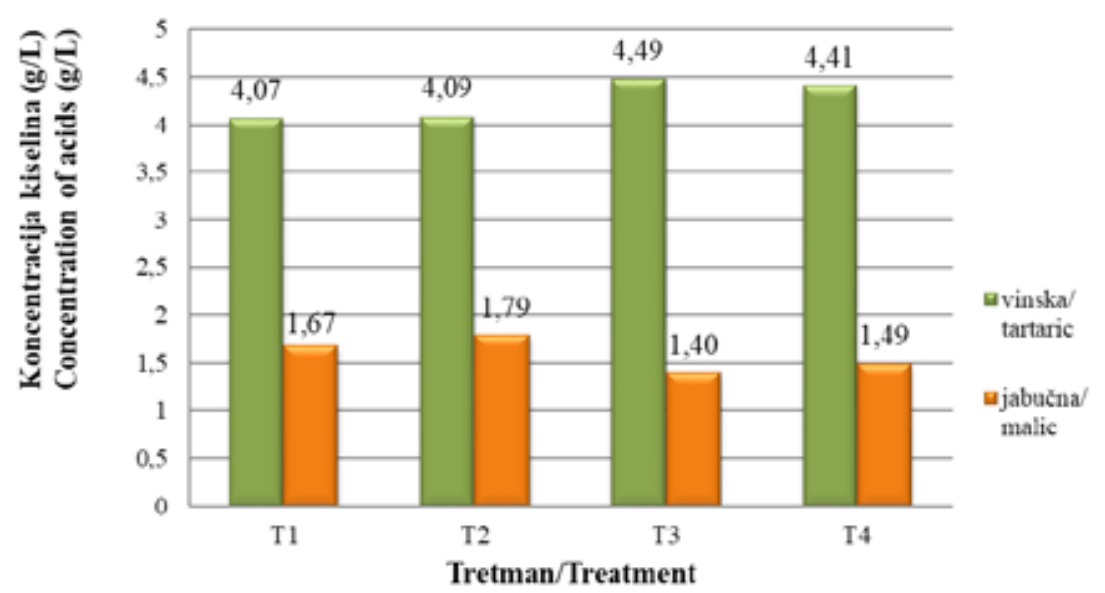

Grafikon 4. Prosječna koncentracija vinske i jabučne kiseline u moštu (g/L) pri primijenjenim tretmanima

Graph 4. Average must tartaratic and malic acid concentrations (g/L) by the applied treatments

$T 1-N P K, T 2-N P K+M g, T 3-N P K+M g+P, i T 4-N P K+M g+P+$ biostimulator 
Čoga i sur. (2009) istraživanjem su utvrdili da postoji jaka povezanost sadržaja P i Mg u lišću sa sadržajem šećera i ukupnom kiselosti mošta cv. 'Sauvignon Blanc' (Vitis vinifera L.). Prema njihovom istraživanju postoji jaka pozitivna korelacija $\mathrm{P}$ i $\mathrm{Mg}$ u lišću sa šećerom u moštu, te negativna sa ukupnim kiselinama. Dok je u ovim istraživanjem utvrđeno da primjenom $P$ folijarno dolazi do smanjenja sadržaja šećera u moštu, a primjenom Mg dolazi do povećanja ukupne kiselosti. Nadalje, iako Palčić (2015.) nije utvrdio značajniji utjecaj gnojidbenih tretmana na sadržaj vinske i jabučne kiseline u vinu 'Malvazije istarske', iz grafikona 4. vidljivo je da sadržaj vinske kiseline u moštu raste, odnosno da sadržaj jabučne pada ovisno o tretmanima.

\section{Zaključak}

Iz dobivenih rezultata može se zaključiti da je tretman T4 - NPK $+\mathrm{Mg}+\mathrm{P}+$ biostimulator imao najpovoljniji utjecaj na osnovni kemijski sastav mošta cv. 'Malvazije istraske' (Vitis vinifera L.), s obzirom da je jedino kod tog tretmana jasno vidljivo da je došlo do smanjenja pH vrijednosti i sadržaja šećera, dok se ukupna kiselosti povećala. Također, isti tretman imao je, pored tretmana T3, najnižu koncentraciju jabučne kiseline i najvišu vinske. Time je ovaj tretman zadovoljio svim zahtjevima koji su bili cilj istraživanja. Dobar rezultat uočen je na tretmanu T3, koji je pored dobrog omjera vinske i jabučne imao niži sadržaj šećera i pH vrijednost od tretmana T1. Tretman T2 imao je značajan utjecaj na ukupnu kiselosti, međutim nije imao povoljan utjecaj na ostala testirana svojstva. Iz istraživanja može se zaključiti da folijarnom gnojidbom je moguće ostvariti pozitivan utjecaj na osnovni kemijski sastav mošta, što je posebice važno za proizvodnju baznog vina za pjenušce u toplijim regijama ili u suhim i vrućim godinama.

\section{Literatura}

Berente B., Reichenbächer M., Danzer K. (2001) Improvement of the HPLC analysis of anthocyanins in red wines by use of recently developed columns. Fresenius Journal of Analytical Chemistry, 371: 68-72.

Bogunović M.; Bensa A. (2005) Tla krša - temeljni čimbenik biljne proizvodnje; U: Biondić, B.; Božičević, J., ur. Zbornik radova. Hrvatski krš i gospodarski razvoj. Gospić/Zagreb: Centar za krš, 41-50

Čoga L., Slunjski S., Herak Ćustić M., Maslać J., Petek M., Ćosić T., Pavlović I. (2009) Influence of Soil Reaction on Phosphorus, Potassium, Calcium and Magnesium Dynamics in Grapevine (Vitis vinifera L.). ACS. Agriculturae conspectus Scientificus, 1/2009/74 (1331-7768); 39-43.

Daudt C.E., Fogaça A. (2008) Effect of tartaric acid upon potassium, total acidity and $\mathrm{pH}$, during the vinification of Cabernet Sauvignon grapes. Ciência Rural, 38 (8), 2345-2350. URL: http://dx.doi.org/10.1590/S0103-84782008000800039 (11.05.2014.) Italjia.

Fregoni M., Fregoni C., Ferrarini R., Spagnolli F. (2008) Chimica viticola-enologica 2a edizione. Reda Edizioni, Torino,

Herak Ćustić M., Gluhić D., Čoga L., Petek M., Gošćak I. (2008) Vine plant chlorosis on unstructured calcareous soils and leaf $\mathrm{Ca}, \mathrm{Mg}$ and $\mathrm{K}$ content. Cereal research communications, 36/2008/1, 439-442.

Ilak Peršurić A.S., Gluhić D., Peršurić Đ. (2006) Istraživanje bioraznolikosti Malvazije Istarske bijele temeljem OIV parametara. Sjemenarstvo, 3/2006/23, 255-272.

Jones J.E., Kerslake F.L., Close D.C., Dambergs R.G. (2014) Viticulture for Sparkling Wine Production: A Review. American Journal of Enology and Viticulture, 65, 407-416. URL:https://www.researchgate.net/publication/267752480_Viticulture_for_Sparkling_Wine_Production_A_Review (07.12.2018.)

Māetić E., Karoḡan Kontić J., Pejić I., Preiner D., Zdunić G., Bubola M., Stupić D., Andabaka Ž., Markovic Z., Šimon S., Žulj Mihaljević M., Ilijaš I., Marković D. (2015) Zelena knjiga: Hrvatske izvorne sorte vinove loze. Državni zavod za zaštitu prirode Zagreb, Hrvatska.

O.I.V. (2007) Compendium of International Methods of Wine and Must Analysis. Vol. 1. O.I.V., Paris, Francuska.

Palčić I. (2015) Utjecaj gnojidbenih tretmana na koncentracije minerala i organskih kiselina u vinu cv. Malvazije istarske (Vitis vinifera L.) s različitih terroira. Doktorski rad. Sveučilište u Zagrebu, Agronomski fakultet.

Roubelakis-Angelakis Kalliopi A. (2009) Grapevine Molecular Physiology \& Biotechnology, Second Edition. Springer Science+Business Media, London, UK.

White R.E. (2003) Soils for Fine Wine. Oxford University Press, Inc., New York, USA.

Zoecklein B.W., Fugelsang K.C., Gump B.H., Nury F.S. (1995) Wine Analysis and Production. Chapman and Hall, New York, USA.

Zoecklein B.W. (2002) A review of Méthode Champenoise Production. Food Chemistry, 129 (3), 1232-1241. URL: https://www.sciencedirect.com/journal/food-chemistry/vol/129/issue/3 (14.07.2018.)

Prispjelo/Received: 20.3.2020.

Prihvaćeno/Accepted: 3.6.2020. 


\title{
Effect of foliar fertilization on cv. Istrian Malvasia (Vitis vinifera L.) must on basic chemical composition
}

\begin{abstract}
'Istrian Malvasia' (Vitis vinifera L.) is one of the most important white varieties in Croatia. Its quality is recognized in Croatia as well as in the whole world. Therefore, producers are increasingly choosing to produce wine and sparkling wine from this variety. The must of base wine for sparkling wine in its composition should satisfy characteristics such as lower $\mathrm{pH}$ and sugar content and higher total acidity with higher tartaric acid than malic acid content. Due to the fact that Istrian Malvasia is grown mainly in Istria, where the climate is Mediterranean, and the most widespread soil is red soil, it is difficult to satisfy all the above characteristics, especially in dry and hot years. Therefore, the aim of this study was to determine the possibility of a positive effect of foliar fertilization on these properties. The present reserch was set on Istrian Malvasia variety on rootstock SO4 in 2013 with four fertilization treatments (T1 - NPK, T2 - NPK + Agromag 6L (6\% MgO), T3 - NPK + Agromag 6L + Phosphorus 30L (30\% P2O5) and T4 - NPK + Agromag $6 \mathrm{~L}$ + Phosphorus $30 \mathrm{~L}+$ Bio PROT) in three replicates per randomized complete block design (RCBD). Overall, must $\mathrm{pH}$ values varied from 3.02 to 3.29, total acidity in the must ranged from 7.80 to $9.03 \mathrm{~g} / \mathrm{L}$, while the sugar content from 76.00 to $81.00^{\circ} \mathrm{Oe}$. The highest determined concentration of tartaric acid was $4.49 \mathrm{~g} / \mathrm{I}$ in the T3 treatment, which also had the lowest determined concentration of malic acid $1.40 \mathrm{~g} / \mathrm{L}$. Treatment T4 had a significant positive effect on all properties.
\end{abstract}

Keywords: magnesium, phosphorus, total acidity, base wines, sparkling wines



